A CASE OF SPLENECTOMY.

BY Sir SPENCER WELLS, BART., WITH

\section{A HISTORY OF THE DISEASE,}

BY W. N. MACCALL, M.D.,

Honorary Physician to the Clinical Hospital for Women and Children, Manchester.

AXD WITH

\section{A REPORT ON THE BLOOD A YEAR AFTER THE OPERATION,}

BY J. DRESCHFELD, M.D., F.R.C.P.,

Professor of Pathology, Victoria University, Manchester.

DouBr has been often expressed whether, after excision of the spleen, the blood would remain in a normal condition. I have already in the Medico-Chirurgical Transactions (vol. lxxi, 1888) shown cause to believe that in one of my successful cases of splenectomy the blood remained normal several months after operation. Splenectomy was performed in December, 1887, and the patient is now in excellent health. But in that case I had not the advantage of a microscopic examination of the blood, which I have in the case I have now the pleasure of laying before the profession, with the kind help of Dr. Maccall and Dr. Dreschfeld.

History of thr CASk, BY Dr. Maccall (dated August, 1888).

Mrs. R., a young Jewish lady, was born in Roumania in July, 1867 , and is therefore now only 21 years of age. At the age of 4 she was attacked by ague, which is endemic in her native place, affecting natives as well as foreigners. She continued to suffer from it more or less for two years, in spite of treatment, and became very anæmic and ailing. The spleen is said to have been then considerably enlarged; but the account of this, obtained from her parents, is somewhat vague. When 6 years old, she came with her parents to reside in England; and, although very ill on the way, she soon regained perfect health. Shortly afterwards I became the medical attendant of the family, and have been ever since. My knowledge of the patient, therefore, extends over nearly fifteen years, during all of which time she has enjoyed good health, so good that I am not sure if I ever had to prescribe for her, and certainly never had occasion to examine her or see her in bed.

She grew up a well-formed, handsome young lady, with fairly good colour, and apparently perfect health. She married about the end of 1886, when fully 18 years of age. As she went to live at some distance from me, I advised her to have a medical attendant living nearer to her. About the end of February, 1887, her mother came to me in distress, saying that the doctor who attended her had discovered an abdominal tumour, which was believed to be either left ovarian or peri-uterine, and that she would like me to see Mrs. $\mathbf{R}$.

Accordingly, on March 4th, 1887, I saw her in consultation with her medical attendant, Dr. Heckscher. I found a roundish, rather firm tumour, about the size of a fist, in the left ovarian region. It was freely movable, and its movement did not affect the uterus. That organ was normally placed, and neither fixed nor dragged. But the os and cervix uteri were rather full, and the patient had missed one menstrual period. My opinion was that there was, most probably, a tumour of the left ovary. But as there was a possibility of beginning pregnancy, it was agreed that we should wait, and Dr. Heckscher should keep her under observation. The patient said that for some years, she could not say how many, she had been aware of a lump in that region, of about half its present size, and freely movable. But as it was quite painless, and caused her no inconvenience, she thought it was natural-something that every one had-and, therefore, had never even mentioned it to her mother or elder sister.

I did not see her again for about six months, but heard frequently that she was very well, and, in spite of advancing pregnancy, not suffering much inconvenience. About the end of August I was asked to attend her in confinement, which
I agreed to on condition that a medical man in the neighbourhood should act with or for me in case of emergency.

On September 4th, 1887, I examined the patient, then about seven months pregnant. I found the fotal heart distinct, the child normally placed, and the tumour a little, but not much, larger, pushed up by the increasing uterus into the left hypcchondriac region, and not causing any inconvenience. I saw her again on September 18th and October 27th, when I noted that, except the advancement of pregnancy, there was no marked change in the local conditions, and her general health was gcod.

On November 9th, 1887, Mrs. R. was confined of a fine healthy boy, the accouchement being in every respect natural, and her after-progress good. As the uterus contracted, the tumour descended; it was freely movable, and not attached to the uterus. After a week it had resumed its old position, and was only slightly larger than before pregnancy began. Mrs. R. suckled her baby, and in about a month went to Southport, but returned on December 16th with a deep-seated abscess in one breast, which pulled her down considerably. In a few weeks she regained her strength, and when I saw her on January 12th, 1888, her health was good, and the condition of the tumour unchanged.

Owing to my own illness, I did not see her again until February 26th, 1888, when I found a very remarkable change in the local condition. My notes say : "The tumour is now centrally situated, lying in front of the uterus, extending from the pubes to the umbilicus, and measuring fully nine inches transversely. It is still painless, fairly firm, and smooth to pressure, and the fingers, pressed firmly behind it at the sides, feel firm rounded edges. It is still slightly movable, and evidently not attached to the uterus. I said: "This is not an ovarian tumour, as I had supposed; I have already decided that it is not uterine, but $I$ am not at all sure what it is." "

I accordingly sent my patient up to Sir Spencer Wells to obtain his opinion. He wrote to me on March 1st, saying he believed the tumour to be an enlarged displaced spleen, and that he could feel the splenic notch.

On re-examining and questioning Mrs. R., and reviewing all the circumstances, I at once accepted Sir Spencer Wells's view of the case as the correct one. $\mathrm{He}$ advised trying iron and quinine for about six weeks, and that Mrs. R. should then see him again. On March 13th, I found matters practically unchanged.

March 29th, 1888. On returning from a few days' holiday, I was asked to see Mrs. R., then on a visit to her mother (who lives near me), as she had suddenly become very much worse. I found her sitting up, her face blanched, pinched, and with an anxious haggard expression, pulse small, over 120 . She said that about thirty-six hours before, on the evening of the 27th, the tumour had begun suddenly to enlarge, and became very painful and tender. She afterwards confessed that this had followed an attempt on her part to force the tumour back into its original free position in the left side. I sent her at once to bed, and found the tumour much increased in size; it measured over 10 inches from side to side, and extended from pubes to ensiform cartilage, quite filling the abdomen anteriorly. The flanks were clear to percussion. The tumour was very hard, and decidedly tender to pressure. The patient complained of dragging pains in the back and thighs. She had not been able to sleep, and had quite lost her appetite. Temperature $98.6^{\circ} \mathrm{F}$. Next day rigors occurred, and the temperature rose to $105^{\circ}$; the slightest touch or movement caused agonising pain. For over a week her condition was very critical; peritonitis accompanied by fever of a hectic or irregularly intermittent type (the temperature ranging from $101^{\circ}$ to over $104^{\circ}$ ) being evidently present. There was also extreme irritability of the stomach, evidenced by very frequent and distressing vomiting. Dr. Lloyd Roberts saw her with me twice during this period. Our opinion was that sudden hæmorrhage, to a large extent, had occurred into the spleen substance, probably not rupturing the splenic capsule, as the flanks remained clear and the tumour was fairly well defined, and that, as a result of the sudden distension, etc., peritonitis had ensued. After about ten days, the temperature became normal, and the other indications of peritonitis subsided. The tumour diminished in size until it was about two-thirds of its largest dimensions. About April 17th, this steady diminution ceased, and various points of softening were detectable. These increased rapidly and coalesced; the accumulating fluid pressing up on the chest, causing dyspncea, and bringing back the distressing vomiting, etc. I suggested tapping to relieve her and gain time, and Sir William Roberts saw her on the 24 th with reference to my suggestion. He thought tapping 
would become necessary, but advised waiting a few days because of the risk of renewed hæmorrhage and other dangers.

May 2, 1838. Mrs. R.'s condition had now become so serious from orthopnœa, distressing vomiting, pain, etc., that it was evident she must be relieved at any hazard. Accordingly, under chloroform, Mr. Hardie and I drew off by the aspirator ten pints of a somewhat thick reddish brown fluid, the operation lasting about two hours. Microscopically, I found this to contain mainly broken-down red blood corpuscles, with very numerous leucocytes. I omitted to say that after accepting the splenic theory of the tumour, I had examined the patient's blood microscopically, and found no very marked increase of the white blood corpuscles, certainly nothing approaching leukamia. After the tapping, Mrs. R.'s condition rapidly improved, but soon the fluid began to reaccumulate in the sac, and increased so quickly that $\mathrm{Mr}$. Hardie and I agreed that the best chance for the patient would be to have the tumour removed at once, or drained, rather than have her physical powers steadily and surely exhausted to the fatal end by repeated tappings and reaccumulations. Accordingly, I wrote to Sir Spencer Wells, describing the state of affairs, and asking if he would undertake the operation. He agreed to do so and fixed Nay 13th, 1888, for the operation. On the 12th I again examined the blood, and found no very marked increase of white corpuscles. About 10 A.M., Mrs. R. was put under ether by Dr. W. S. Scott, and Sir Spencer Wells proceeded to operate, assisted by Mr. Hardie, Mr. Walsh, and myself. In the course of the operation the cyst wall ruptured, and a quantity of reddish-brown fluid rushed out, similnr to that removed by aspiration, but rather thinner. It could not be measured, but apparently was as much, or nearly as much, as that removed by aspiration, probably amounting to eight or ten pints. The solid part of the tumour, consisting of hypertrophied spleen tissue, weighed four pounds. There were extensive adhesions to intestines, uterus, etc. Many of these were separable, but a part in front was so firmly adherent that it was deemed wiser to leave a portion of the cyst wall, about three to four inches from above downwards, and two to three from side to side, and a quarter of an inch thick. The patient was so exhausted, that to have prolonged the operation by separating this adhering portion of the splenic capsule would have been very hazardous. Sir Spencer Wells decided not to drain, and, after securing the splenic vessels by silk ligature, stitched up the wound with fine silk, including sac-wall, peritoneum, and integument; but he arranged with me that if fluid formed, part of the wound should be reopened. The operation, which lasted fifty minutes, was performed under the carbolic spray, and the wound was dressed antiseptically. Scarcely any blood was lost except from the splenic pulp, but the patient was unuch exhausted after the operation; pulse over 150 and very feeble.

The history of the next week may be briefly summed up. For two days she remained very collapsed; the pulse remaining small and rapid, over 120 . Then she began to improve sensibly, and continued to do so steadily, the pulse gaining force and becoming slower. The temperature on the 14th, the day after the operation, once reached $100^{\circ} \mathrm{F}$.: but at all other times, although taken from four to six times daily, it was normal, or slightly sub-normal. On the 16 th she complained of some smarting at the wound, and I dressed it. There was no irritation, redness, or tenderness, and after merely changing the dressings, she felt quite comfortable. On the morning of the 19th she again complained of the same, and I changed the dressings. I found some swelling of the abdo. men, chiefly on the right side of the wound, doubtfully dull to percussion, and a moderate amount of flatulent distension. The wound looked healthy, no dragging of stitches, and pressure nowhere caused pain. The patient felt quite well, pulse and temperature were normal, and I therefore decided not to remove stitches, but to dress daily and watch. At night, when I saw her, she said she had been quite comfortable all day; she felt and looked well.

Next morning, Sunday, May 20th, just a week after the operation, I found my patient very much upset. The nurse said that in the early morning a quantity of thin, greyish-yellow discharge had begun oozing from the wound, soaking through the dressing, and had continued ever since. The smell was most offensive, of which my nose had made me aware before I entered the room. Mrs. R., who is of a highly nervous temperament, was much excited and restless, with anxious look and rapid pulse, but the temperature was normal. I dressed it temporarily, and later on, with Professor Sinclair, of Victoria Lniversity, removed a stitch in the centre of the wound, when a quantity of discharge gushed out with some force. We then washed it out thoroughly with perchloride of mercury solution (1 in 1,000), inserted an india-rubber drainage tube, and dressed with sublimate wood-wool. The patient continued fairly well until about $2 \mathrm{~A} . \mathrm{M}$. on Monday, when vomiting, very frequent and with distressing straining, set in Finding that everything was rejected (and as the bowels had been moved for the first time), I decided to trust entirely to rectal alimentation, and for the succeeding thirty-six hours nothing was given by the mouth but an occasional tablespoonful of iced champagne. By the rectum, nutrient and stimulant enemata were administered every three or four hours, with an opiate when required. The vomiting ceased about 9 o'clock in the evening, but the patient was so exhausted that I was afraid she would die. Next day she rallied slightly, and on Wednesday she was decidedly better, and we began cautiously to feed by the mouth again. By the end of the week she was as well as before this disturbance. At no time was the temperature above the normal, but it occasionally got below $97^{\circ} \mathrm{F}$. In syringing the pus-forming cavity it was clear that there was no communication with the general peritoneal cavity.

The subsequent history is simply that of uninterrupted improvement, rapid as to the patient's general health, slower as to the local condition. I dressed the wound daily as above, and the sac gradually contracted, becoming a sinus. When I last saw her at her own home on July 22nd, she looked and felt perfectly well, and only a small superficial sore remained. Menstruation has occurred twice since the operation, normal in colour, but less in amount than formerly, with just a month's interval between the periods. She feels no pain, dragging, or inconvenience of any kind. No one to look at her would suppose that she has so recently been three months in bed; that during those three months she has been three several times at death's door, and lost a very large amount of blood. She does not seem, so far, to suffer from the absence of her spleen; if anything. I should say she has regained her colour more rapidly than most people who possess spleens manage to do after severe hæmorrhage.

I have not thought it necessary to go into the details of nursing, etc., but there was frequent irritability of stomagh and the question of alimentation was a most serious one throughout, taxing all our skill and generalship. The care and watchfulness of the two nurses contributed largely to the fortunate ending of this extremely interesting but very trying case.

May 14th, 1889. I have to-day seen Mrs. R. just a year after the operation. Since the date of my last report she has enjoyed perfect health in every respect. Her colour, if it differs, is, if anything, better than before. She has neither pain, dragging, nor inconvenience of any kind, and can walk, dance, or exert herself in any way as well as ever she did in her life. The scar is firm, and pressure through the abdominal walls gives rise to no abnormal sensation. Her baby, now eighteen months old, is a very fine little fellow. Menstruation is, and has been ever since the operation, perfectly regular, but whereas before the splenectomy it was decidedly excessive in quantity, it now is quite normal in amount and duration.

Copy of DR. DReschfeld's Report on the Examination of THE BLOOD.

The blood to the naked eye had a perfectly normal appearance, and coagulated in the usual way. Examined microscopically, the blood appeared perfectly normal. The red blood corpuscles were of normal size and appearance; no poikilocytes, very few microcytes. The leucocytes were present in the normal proportion. They were of normal size, and, on the addition of acetic acid, showed compound nuclei. Examined with Gowers's hamocytometer, the average of several examinations showed $4,500,000$ red blood corpuscles per cubic millimètre, and about 7,000 colourless corpuscles per cubic millimètre. Examined with hæmoglobinometer, the quantity of hæmoglobin was between 75 and 80 per cent. [Dated June 21st, 1889, more than a year after operation.]

Note BY SIR Spexcer Wells.

I need not add more to the above interesting reports of Dr. Maccall and Dr. Dreschfeld than to say that on June 7 th, 1889 , Mrs. R. called on me in London in excellent health. The abdominal cicatrix was firm, and nothing abnormal could be discovered either in the abdomen or pelvis. She was about to travel on the Continent. Menstruation quite regular. 